\title{
A morphological and biochemical evaluation of the effects of quercetin on experimental sciatic nerve damage in rats
}

\author{
SIBBLL TÜREDI ${ }^{1}$, ESIN YULUĞ $^{1}$, AHMET ALVER $^{2}$, AKIN BODUR $^{2}$ and IMRAN INCE ${ }^{2}$ \\ Departments of ${ }^{1}$ Histology and Embryology and ${ }^{2}$ Medical Biochemistry, \\ Faculty of Medicine, Karadeniz Technical University, Trabzon 61080, Turkey
}

Received July 22, 2017; Accepted November 3, 2017

DOI: $10.3892 / \mathrm{etm} .2018 .5824$

\begin{abstract}
The present study evaluated the neuroprotective and antioxidant effects of quercetin in a rat model of sciatic nerve crush injury using histopathological, morphometric and biochemical methods. A total of 48 male Sprague Dawley rats, aged 10-12 weeks old were randomly divided into eight groups, consisting of two sham groups (S-7, S-28), three quercetin-treated groups (Q-7, Q-28; $200 \mathrm{mg} / \mathrm{kg} / 7$ days), trauma (T-7, T-28; 1 min sciatic nerve crush injury) and three trauma+quercetin groups (T+Q-7, T+Q-28; trauma+quercetin $200 \mathrm{mg} / \mathrm{kg} / 7$ days). Rats were sacrificed on day 7 or 28 . Oxidant-antioxidant biochemical parameters in nerve tissues from all groups were analyzed using histopathological staining with toluidine blue and Masson's trichrome. DNA fragmentations were identified using terminal deoxynucleotidyl transferase deoxyuridine triphosphate nick-end labeling in cells from each tissue sample. Degeneration of the axons and myelin sheath, the breakdown of the concentric lamellar structure of the myelin sheath and axonal swelling were observed in groups T-7 and T-28. Myelin sheath thicknesses, nerve fiber diameters and the number of myelinated nerve fibers decreased, while the apoptotic index (AI) increased in the T-7 and T-28 groups. However, it was observed that nerve regeneration began in the $\mathrm{T}+\mathrm{Q}-7$ and $\mathrm{T}+\mathrm{Q}-28$ groups compared with the sham groups, together with the healing of cellular damage and axonal structure and a decrease in the AI. Malondialdehyde and superoxide dismutase activity did not differ significantly between the T-7 and S-7 groups. However, catalase activity significantly decreased in the T-28 group when compared with the sham 7 day group. Tissue malondialdehyde levels significantly increased, while serum catalase activity increased in the T+Q-7 group compared with
\end{abstract}

Correspondence to: Miss Sibel Türedi, Department of Histology and Embryology, Faculty of Medicine, Karadeniz Technical University, Basic Medical Science Building, 1 Farabi Street, Trabzon 61080, Turkey

E-mail: sibelturedi3361@hotmail.com

Key words: sciatic nerve injury, quercetin, lipid peroxidation, apoptosis the T-7 group. These results suggest that quercetin has beneficial effects on nerve regeneration and may shorten the healing period in crush-type sciatic nerve injuries.

\section{Introduction}

Significant damage may occur to the distal and proximal ends of the sciatic nerve due to trapping, crushing or stretching induced by accident or injury (1). Ineffective treatment of nerve injuries may lead to partial or complete loss of sensory, as well as motor and autonomic function (2). Loss of productivity, socioeconomic and psychological problems may be observed in individuals with nerve damage that results in functional impairment $(2,3)$.

Crush injuries may cause the total loss of motor and sensory functions in the sciatic nerve $(2,4)$. Crush-type injuries in rats are an auxotrophic model frequently used to investigate nerve regeneration following injury and are characterized by the complete severing of the nerve axon and myelin. Morphological, electrophysiological and functional effects may differ depending on the degree, duration and characteristics of the induced damage. Acute short-term compression results in nerve ischemia, hypoxia, edema, an increase in vascular permeability and the blockage of axoplasmic flow (5). Following nerve injury, a process known as Wallerian degeneration begins at the site of the axon distal to injury $(4,5)$. However, persistent crush adversely affects microcirculation. Peripheral neural microcirculation, which serves an important role in nerve regeneration, affects nerve injury and regeneration, the blood-oxygen supply, neurotrophic effects, the maintenance of neural conduction and axonal transport (4). Biochemical and functional changes may occur under these conditions, including changes in the expression of myelin proteins (5). Reperfusion may occur and the subsequent decrease in pressure on nerve tissue leads to the high-pressure redeposition of oxygen and nutrients and the increased formation of free radicals, which leads to lipid peroxidation (LPO) and tissue damage (3). The cumulative impact of ischemic and mechanical processes in this type of nerve damage may be more pronounced than their individual effects $(3,6,7)$. Although peripheral nerves are capable of undergoing regeneration following injury, this process and the post-traumatic results are typically slow and weak. Peripheral nerve trauma is therefore a significant cause of morbidity (6). A large 
amount of research has been conducted aiming to reduce the effects of peripheral nerve damage; however, to the best of our knowledge, no effective therapeutic strategies have been identified (6).

Quercetin (3,3',4',5,7-penta-hydroxy flavone) is a ubiquitous plant flavonoid compound from the polyphenolic group (8). It is found in many fruits, vegetables and aromatic herbs, including onions, broccoli, green tea, Ginkgo biloba and St. Johns-wort (Hypericum perforatum) (8). Previous pharmacological studies have reported that quercetin has powerful antioxidant, antiangiogenic, anti-inflammatory, neuroprotective and anti-apoptotic properties $(8,9)$. Due to its powerful antioxidant and anti-inflammatory activity, it has been suggested that quercetin may prevent various diseases, including diabetes, cancer and obesity (10). The effectiveness of quercetin at treating ischemic injuries has also been identified; quercetin is neuroprotective in cerebral ischemia, as it decreases matrix metalloproteinase-9 levels and reduces free radical production (10). Another study reported that quercetin exhibited neuroprotective effects against aluminum-induced cognitive impairments in rats (11).

The aim of the present study was to evaluate the neuroprotective and antioxidant efficacy of quercetin in an experimental rat model of nerve crush injury, using histomorphometric and biochemical parameters to assess its effects.

\section{Materials and methods}

Animals. A total of 48 male Sprague-Dawley rats (10-12 weeks old, weighing 250-300 g) were used in the present study. Rats were obtained from the Karadeniz Technical University Medical School Experimental Research Center (Trabzon, Turkey). All animals were housed in a controlled laboratory environment at room temperature $\left(22 \pm 2^{\circ} \mathrm{C}\right)$ in $50 \pm 10 \%$ humidity and under a $12 \mathrm{~h}$ light/dark cycle. Standard lab chow and water were provided ad libitum throughout the experiment. All animals received humane care according to the criteria outlined in the Guide for the Care and Use of Laboratory Animals published by the National Institutes of Health (12) and the present study was approved by the Institutional Animal Ethical Committee of Karadeniz Technical University (license no. 30.06.2015/4; 12.05.2016/272).

Study groups. The animals were assigned into one of the 8 following groups ( $\mathrm{n}=6 /$ group): A sham 7-day group (S-7), in which, a surgical incision was made and closed on the first day of the experiment and animals were sacrificed on day 7; a sham 28-day group (S-28), in which a surgical incision was made and closed on the first day of the experiment and animals were sacrificed on day 28; a quercetin 7-day group (Q-7), in which a previously utilized dosage of $200 \mathrm{mg} / \mathrm{kg}$ quercetin (13) (Sigma-Aldrich; Merck KGaA, Darmstadt, Germany) was dissolved in $0.5 \%$ dimethyl sulfoxide (DMSO; Merck KGaA) and administered intragastrically by the oral route from the first day of the experiment for 7 days. Rats were then sacrificed on day 7; a quercetin 28-day group (Q-28), in which $200 \mathrm{mg} / \mathrm{kg}$ quercetin dissolved in $0.5 \%$ DMSO was administered intragastrically by the oral route for 7 days. Rats were sacrificed on day 28; a trauma 7-day group (T-7), in which the sciatic nerve was exposed by a surgical incision and crush injury was induced. The incision was closed and the rats were sacrificed on day 7; a trauma 28-day group (T-28), in which the sciatic nerve was exposed by a surgical incision and crush injury was induced. The incision was closed and the rats were sacrificed on day 28; a trauma+quercetin therapy 7-day group (T+Q-7), in which the sciatic nerve was exposed by a surgical incision and crush injury was induced. The incision was closed and $200 \mathrm{mg} / \mathrm{kg}$ quercetin dissolved in 0.5\% DMSO was administered intragastrically by the oral route for 7 days. Rats were sacrificed on day 7; a trauma+quercetin therapy 28-day group (T+Q-28), in which the sciatic nerve was exposed by a surgical incision and crush injury was induced. The incision was closed and $200 \mathrm{mg} / \mathrm{kg}$ quercetin dissolved in 0.5\% DMSO was administered intragastrically by the oral route for 7 days. Rats were sacrificed on day 28 .

Surgical procedures. All experimental procedures were performed with the rats in a prone position under anesthesia with ketamine $\left(90 \mathrm{mg} / \mathrm{kg}\right.$; Ketalar ${ }^{\circledR} 50 \mathrm{mg} / \mathrm{kg}$; Pfizer Inc., New York, NY, USA) and xylazine (10 mg/kg; Rompun ${ }^{\circledR} 2 \%$; Bayer, Pittsburgh, PA, USA), which were administered intraperitoneally. The right lateral femoral region was cleaned with an antiseptic solution and a surgical incision was made using a scalpel. A unilateral muscular incision was made from the greater trochanter to the mid-femur. For the sham groups, the sciatic nerve was exposed and closed and no further procedures were performed. For the trauma groups, the sciatic nerve was exposed following muscle incision. Crush injury was then induced by attaching a microclamp to the sciatic nerve for $1 \mathrm{~min}$. The skin was then closed with a double layer of 4.0 silk sutures to the subcutaneous tissue to prevent potential suture opening and infection in the area of the incision during subsequent stages of the experiment. Following the surgical procedure, rats were left to heal for 7- and 28-days depending on the group they had been assigned to. The time points of 7- and 28-days were selected to analyze the effects of quercetin in a rat model of sciatic nerve injury as degeneration in the myelin sheath becomes apparent after 36-48 $\mathrm{h}$ and axon continuity is typically lost $48-96 \mathrm{~h}$ following injury when impulse transmission is impaired $(14,15)$. Schwann cells and macrophages work together during phagocytosis to clean the wound site in a process that lasts between 1 week and several months. Additionally, degenerated nerve remnants are typically eliminated over 5-8 weeks (16). Therefore, 7- and 28-day intervals were used to assess the early and late effects of the degeneration process in the nerve crush injury model.

At the end of the experimental period, sciatic nerve tissue was removed from the proximal and distal aspects and blood serum specimens were placed into tubes containing EDTA without anticoagulant for subsequent biochemical parameter analysis. Serum samples were obtained following the centrifugation at $3,000 \mathrm{x} \mathrm{g}$ for $10 \mathrm{~min}$ at room temperature and then stored at $-80^{\circ} \mathrm{C}$ prior to further analysis. Extracted sciatic nerve tissues were divided into two parts: Half was processed prior to histological analysis and the other half was placed in an Eppendorf tube for biochemical analyses and stored at $-80^{\circ} \mathrm{C}$.

Histopathological preparation and evaluation of rat sciatic nerves. Osmium tetroxide $\left(\mathrm{OsO}_{4}\right.$; abcr $\mathrm{GmbH}$, Karlsruhe, Germany) induces good fixation of myelinated axons at the 
peripheral nerve and toluidine blue was used for staining, as previously described (17). Briefly, tissue samples taken $0.5 \mathrm{~cm}$ distally to the sciatic nerve injury were fixed with $2.5 \%$ glutaraldehyde (Merck KGaA) in a 0.4 M PBS solution ( $\mathrm{pH} 7.4$ ) for $4 \mathrm{~h}$ at $4^{\circ} \mathrm{C}$. Post-fixation, tissue samples were fixed in $1 \% \mathrm{OsO}_{4}$ for $1 \mathrm{~h}$ at $4^{\circ} \mathrm{C}$ and subsequently passed through an increasing series of alcohol prior to embedding in epoxy resin. Tissue sections were cut into $0.5-\mu \mathrm{m}$-thick sections using a Leica Reichert Ultracut R ultramicrotome (Leica Microsystems $\mathrm{GmbH}$, Wetzlar, Germany) and stained at $50-75^{\circ} \mathrm{C}$ for $30 \mathrm{sec}$ with toluidine blue.

Subsequently, tissue samples were obtained $0.5 \mathrm{~cm}$ distally to the sciatic nerves. These were then fixed in $10 \%$ formalin at room temperature for 4 days, processed using routine histological procedures and embedded in paraffin. Sections $5 \mu \mathrm{m}$-thick were sliced from paraffin blocks using a fully automated microtome (Leica Microsystems GmbH). Sections were stained with Masson's Trichrome using the Masson Trichrome Stain kit-methyl/aniline blue according to the manufacturer's protocol, (Atom Scientific, Cheshire, UK) prior to morphological and morphometric analyses. Morphometric analysis of the sciatic nerve sections, the numbers of myelinated nerve fibers, the myelin sheath thickness and nerve fiber diameter were measured in five distinct areas from each section. All slides were photographed using an Olympus BX 51 light microscope (Olympus Corporation, Tokyo, Japan) at a magnification of x100 and analyzed using Analysis 5 Research software 2.8 (Olympus Soft Imaging Solutions GmbH, Münster, Germany).

Terminal deoxynucleotidyl transferase deoxyuridine triphosphate nick-end labeling (TUNEL) assay. A TUNEL assay was used to analyze apoptosis in the sciatic nerve tissue specimens and DNA fragmentations were identified in cells from each tissue. TUNEL staining of sections was performed using an in situ cell death detection kit (Roche Diagnostics $\mathrm{GmbH}$, Mannheim, Germany) according to the manufacturer's protocol. Apoptotic evaluation from the TUNEL-stained slides was performed using a light microscope at a magnification of $x 400$ in five random fields of view. Homogeneously stained TUNEL (+) Schwann cells with no necrotic areas were defined as apoptotic. Apoptotic and normal cells were recorded by counting 100 Schwann cells in five areas in each tissue at a magnification of $\mathrm{x} 400$. The apoptotic index (AI) was then calculated using the formula $\mathrm{AI}=[\mathrm{TUNEL}(+)$ cell number/total cell number] x100.

Biochemical analyses and techniques employed. Serum and sciatic nerve tissue malondialdehyde (MDA) levels were measured using previously described methods $(18,19)$. The red color resulting from the reaction between thiobarbituric acid and the lipid peroxidation product MDA was measured spectrophotometrically and serum MDA levels were expressed as $\mathrm{nmol} / \mathrm{ml}$. MDA levels in sciatic nerve tissue were determined using a method based on calculating the absorbance of the color of the complex formed by MDA with thiobarbituric acid in an acidic environment at $532 \mathrm{~nm}$ using a VERSA max tunable microplate reader (Molecular Devices, LLC, Sunnyvale, CA, USA) and MDA levels were expressed as nmol/g wet tissue.

Sciatic nerve tissue- and serum catalase (CAT) levels were determined using a method based on measuring the absorbance of the yellow complex formed by ammonium molybdate with $\mathrm{H}_{2} \mathrm{O}_{2}$ at $405 \mathrm{~nm}$ as previously described (20) and the results was expressed as U/mg protein. Sciatic nerve tissue and serum superoxide dismutase (SOD) activity was determined using the method described by Sun et al (21). The absorbance of the purple formazan molecule forming as a result of the reduction of nitroblue tetrazolium by $\mathrm{O}_{2}$.'s formed by the xanthine-xanthine oxidase was measured at $560 \mathrm{~nm}$ using a VERSA max tunable microplate reader. SOD activity was divided by the total protein level and that expressed as U/mg protein. Glutathione (GSH) levels were determined using the method described by Ellman (22). This method is based on derivatization of GSH with 5,5'-dithiobis 2-nitrobenzoic acid (Sigma-Aldrich) and the formation of a yellow complex, which was measured at $410 \mathrm{~nm}$ using a VERSA max tunable microplate reader.

Statistical analysis. The data from the present study was analyzed using SPSS software version 22 (IBM Corp., Armonk, NY, USA). Compatibility with normal distribution was examined using the Shapiro-Wilk test. The Kruskal-Wallis test was used to compare multiple variables in independent groups not exhibiting normal distribution and the Mann-Whitney U test was used to compare two-way variables. The Friedman test was applied to compare more than two variables in dependent groups not exhibiting normal distribution and a post-hoc Wilcoxon test was utilized for the comparison of two-way variables. Values obtained from variables were expressed as the mean \pm standard deviation and $\mathrm{P}<0.05$ was considered to indicate a statistically significant difference.

\section{Results}

Rat body weight. The body weight of the rats increased over time from baseline during the 4-week study period in all groups (Table I), however there was no significant variation in body weight among all groups.

Histopathological observations in sciatic nerve tissue. Histopathological analysis of the sciatic nerve tissues from all groups was performed using Masson's trichrome and toluidine blue staining of semi-thin sections. Microscopic examination of the sciatic nerve sections from groups S-7, S-28, Q-7 and Q-28 revealed impairment of the myelin sheath in certain sections; however the sciatic nerve maintained its normal morphological structure (Figs. 1 and 2). Additional trauma images were presented to clarify the damage caused by the trauma model (Fig. 1; T-7-A, -B, -C; T-28-A, -B, -C). In the T-7 group, it was observed that the nerve was surrounded by epineurium (Fig. 2), occasional fibrotic tissue (Fig. 2) beneath the epineurium invaginating the perineurium and there was occasional loss of integrity in the perineurium (Fig. 1). In the majority of myelinated axons, the axon and myelin sheath were fully degenerated. Furthermore, expansion in the axons, occasional invagination of the myelin sheath into the axon, axonal swelling and severe compromise of the normal concentric lamellar structure of the myelin sheath were observed (Fig. 1). The presence of mast cells and capillary vessels was also observed between the myelinated axons (Fig. 2). These results indicate that Wallerian degeneration occurred (Figs. 1 and 2). 
Table I. Body weights of rats in all groups throughout the experimentation period.

\begin{tabular}{llllll}
\hline & \multicolumn{5}{c}{ Body weight $(\mathrm{g})$} \\
\cline { 2 - 6 } Group & \multicolumn{1}{c}{ Day 0 } & \multicolumn{1}{c}{1 week } & \multicolumn{1}{c}{2 weeks } & 3 weeks & 4 weeks \\
\hline S-7 & $292.85 \pm 10.65$ & $298.30 \pm 9.62$ & $301.88 \pm 8.93$ & $309.60 \pm 8.83$ & $313.38 \pm 8.66$ \\
S-28 & $294.06 \pm 9.21$ & $299.34 \pm 8.78$ & $304.22 \pm 8.99$ & $311.24 \pm 10.45$ & $313.67 \pm 8.57$ \\
Q-7 & $292.80 \pm 10.93$ & $297.49 \pm 11.28$ & $299.16 \pm 9.53$ & $306.83 \pm 9.30$ & $313.16 \pm 7.33$ \\
Q-28 & $295.47 \pm 13.47$ & $299.76 \pm 13.16$ & $305.05 \pm 13.05$ & $314.16 \pm 11.08$ & $317.66 \pm 9.75$ \\
T-7 & $291.81 \pm 12.26$ & $299.34 \pm 14.05$ & $309.83 \pm 13.49$ & $315.33 \pm 10.01$ & $319.16 \pm 8.88$ \\
T-28 & $292.76 \pm 12.02$ & $298.23 \pm 11.31$ & $306.33 \pm 10.91$ & $311.50 \pm 11.20$ & $315.66 \pm 8.73$ \\
T+Q-7 & $296.97 \pm 14.55$ & $301.20 \pm 12.97$ & $308.50 \pm 15.48$ & $311.33 \pm 14.30$ & $313.33 \pm 13.07$ \\
T+Q-28 & $296.42 \pm 12.64$ & $300.26 \pm 12.69$ & $308.16 \pm 9.76$ & $311.33 \pm 10.40$ & $315.66 \pm 9.13$ \\
\hline
\end{tabular}

Data are expressed as mean \pm standard deviation. $\mathrm{n}=6$ /group. S-7, sham 7-day group; S-28, sham 28-day group; Q-7, quercetin 7-day group; Q-28, quercetin 28-day group; T-7, trauma 7-day group; T-28, trauma 28-day group; T+Q-7, trauma+quercetin therapy 7-day group; T+Q-28, trauma+quercetin therapy 28 -day group.
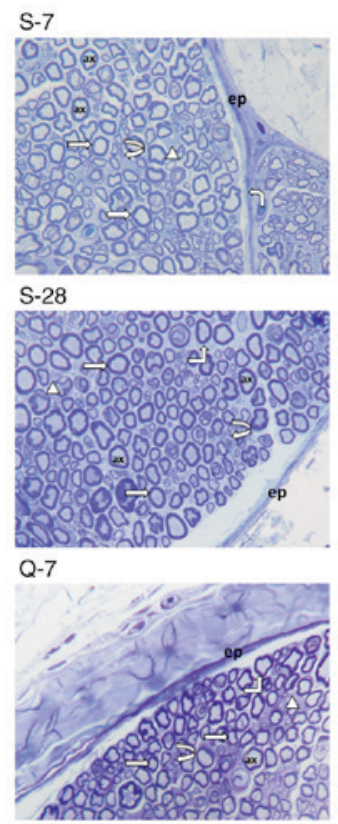

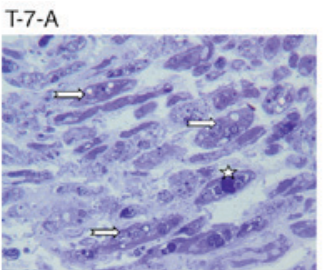

T-28-A

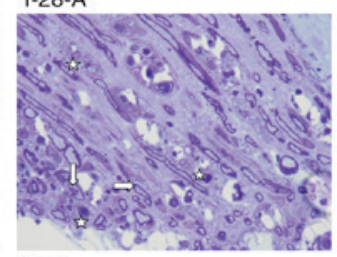

Q-28

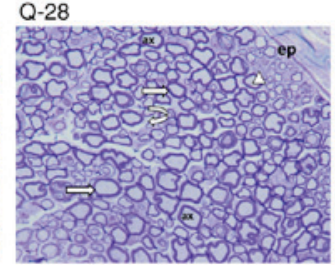

T-7-B

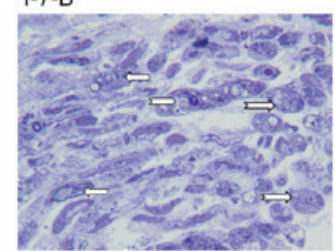

T-28-B

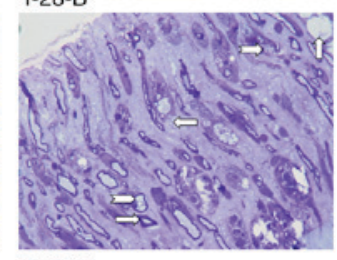

$\mathrm{T}+\mathrm{Q}-7$

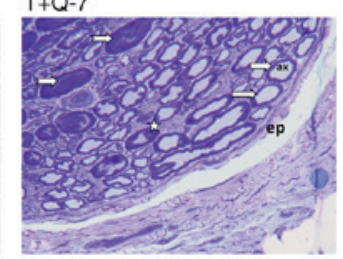

T-7-C

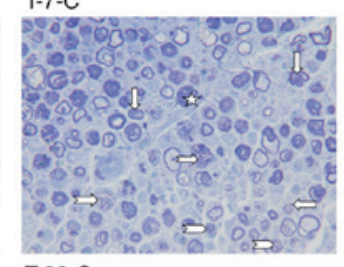

T-28-C

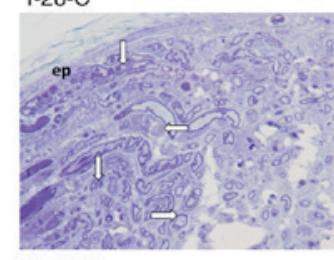

$\mathrm{T}+\mathrm{Q}-28$

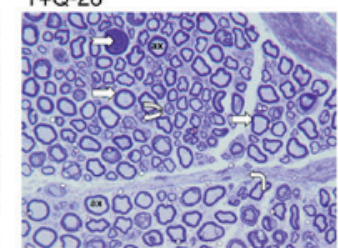

Figure 1. Toluidine blue staining was performed on sciatic nerve tissue sections and representative images of the results from each group are presented. Notable features are indicated on the figure as follows: Epineurium (ep), perineurium (twisted arrow), endoneurium (upward-twisted arrow), axon (ax), myelinated nerve fiber (right arrow), few myelinated nerve fibers (left-twisted arrow), unmyelinated nerve fiber (arrowhead), myelin sheath and axon degeneration (right notched arrow), axonal swelling (star), axon dilatation (upward-arrow), myelin sheath invaginated into the axon (downward-arrow), disorganization in the concentric lamellar structure of the myelin sheath (left arrow), separation in the concentric lamellae of the myelin sheath (angled double separator). Magnification, x100. S-7, sham 7 day group; S-28, sham 28 day group; Q-7, quercetin 7 day group; Q-28, quercetin 28 day group; T-7-A, -B and -C; trauma 7 day group images -A, -B and -C; T-28-A, -B and -C, trauma 28 day group images -A, -B and -C; T+Q-7, trauma+quercetin 7 day group; T+Q-28, trauma+quercetin 28 day group.

In the T-28 group, mild fibrotic tissue growth was observed beneath the epineurium surrounding the nerve (Fig. 2). In some myelinated axons, the axon and myelin sheath were degenerated, the normal concentric lamellar structure of the myelin sheath was impaired and the myelin sheath was invaginated into the axon (Fig. 1). When the morphology of the T-28 group was compared with that of the T-7 group, the presence of nerve fibers indicating that the regeneration process had begun was observed in the T-28 group (Figs. 1 and 2). Light microscopic examination of semi-thin sciatic nerve sections from the T+Q-7 group revealed that regeneration had begun in myelinated nerve fibers and that the axon and myelin sheath structures were also included within this process. In addition, in some myelinated nerve fibers, the normal structure of the myelin sheath around the axon was impaired, the myelin sheath and axon were degenerated and the presence of phagocytic cells contiguous to these areas was observed. The degeneration structures of nerve fibers intensively observed in the T-7 group had begun to decrease in this group; however, the regeneration process was still ongoing (Fig. 1). Microscopic examination of semi-thin sciatic nerve sections from the T+Q-28 group revealed visible myelinated nerve fiber regeneration compared 

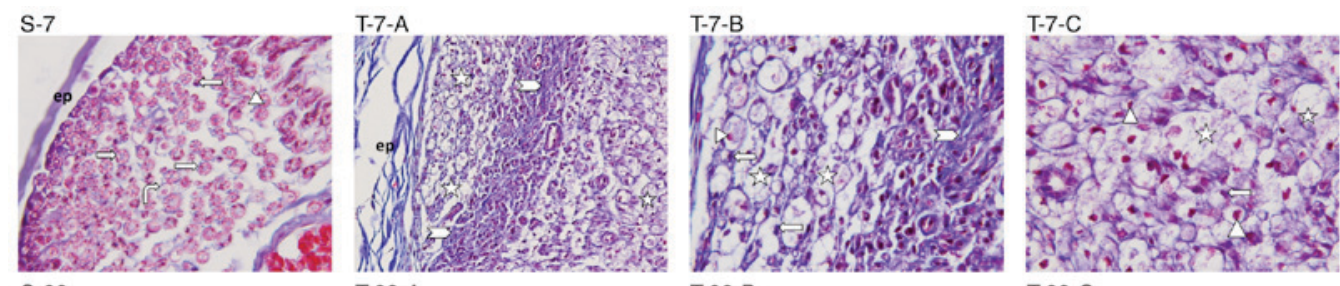
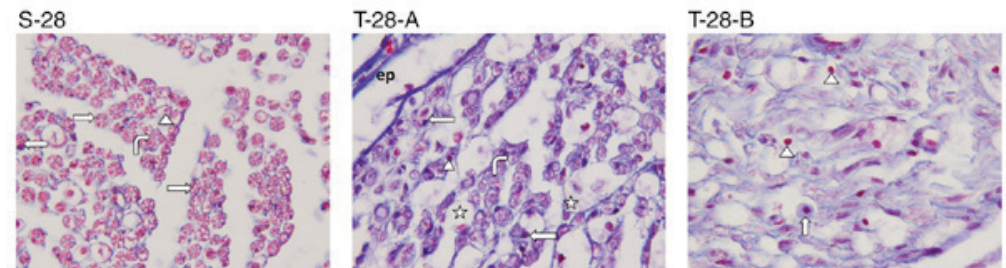

$\mathrm{T}-28-\mathrm{C}$

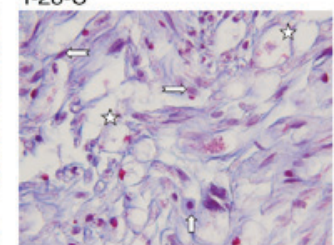

$\mathrm{T}+\mathrm{Q}-7$

$T+Q-28$
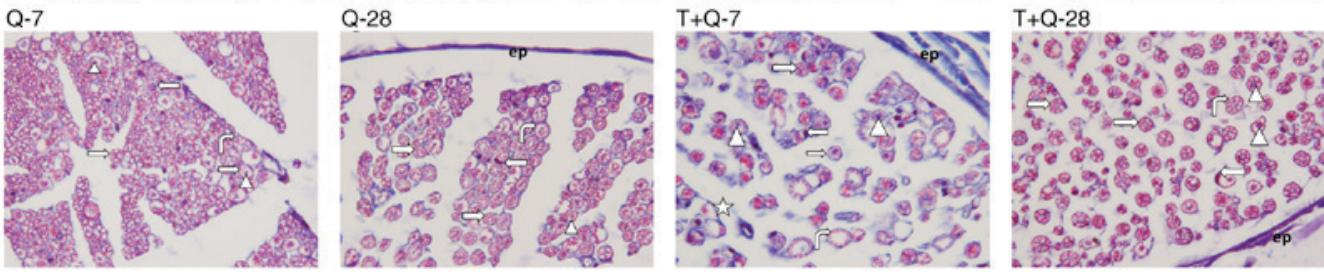

Figure 2. Masson's trichrome staining was performed on sciatic nerve tissue sections and representative images of the results from each group are presented. Notable features are indicated on the figure as follows: Myelinated nerve fiber (right arrow), axon (arrow head), Schwann cell nucleus (left arrow), epineurium (ep), endoneurium (twisted arrow), mast cell (upward arrow), fibroblast (right notched arrow), fibrocytes (left notched arrow), axon and myelin sheath degeneration (star), axonal swelling (star), fibrotic tissue (angled double separator Magnification, x100. S-7, sham 7 day group; S-28, sham 28 day group; Q-7, quercetin 7 day group; Q-28, quercetin 28 day group; T-7-A, -B and -C; trauma 7 day group images -A, -B and -C; T-28-A, -B and -C, trauma 28 day group images -A, -B and $-\mathrm{C} ; \mathrm{T}+\mathrm{Q}-7$, trauma+quercetin 7 day group; T+Q-28, trauma+quercetin 28 day group.

with the T-28 group, regenerated axonal bundles progressing from the periphery and occasional commencement of a return to normal structure in terms of axonal structure and the myelin sheath. Compared with the T+Q-7 group, the axonal structure and myelin sheath in the $\mathrm{T}+\mathrm{Q}-28$ group were significantly closer to normal and the application of quercetin made a positive contribution to the regeneration process (Figs. 1 and 2).

Morphometric observations. Morphometric results concerning myelin sheath thickness, nerve fiber diameter and the number of myelinated nerve fibers in sciatic nerve tissues from the groups are presented in Table II. The myelin sheath thickness and myelinated nerve fiber numbers in the T-7 and T-28 groups were significantly decreased compared with the S-7 and S-28 groups, respectively (all $\mathrm{P}<0.05$ ). No significant differences in morphology were observed between the T-7 and T+Q7 groups. However, the T+Q-28 group exhibited a significantly increased number of myelinated nerve fibers and significantly increased nerve fiber diameters compared with the T-28 group $(\mathrm{P}<0.05)$. Furthermore, the T+Q-28 group had a significantly increased number of myelinated nerve fibers and nerve fiber diameter compared with the T-28 and T+Q-7 groups (all $\mathrm{P}<0.05$ ).

Immunohistochemical findings. AIs of the sciatic nerve tissues were determined by a TUNEL assay (Fig. 3) and the results are presented in Table II. AI values in Schwann cells from the sciatic nerve tissue were significantly increased in the T-7 and T-28 groups compared with the S-7 and S-28 groups, respectively $(\mathrm{P}<0.05)$. In addition, in terms of $\mathrm{AI}$, no differences were observed between the T-7 and T-28 groups and the S-7 and $\mathrm{S}-28$ groups. The $\mathrm{AI}$ in the $\mathrm{T}+\mathrm{Q}-7$ group was significantly lower than in the $\mathrm{T}-7$ group $(\mathrm{P}<0.05)$. Additionally, the AI was significantly decreased in the T+Q-28 group compared with the T-28 group $(\mathrm{P}<0.05)$. No significant differences in the AI were observed between the T+Q-28 and T+Q-7 groups.

Biochemical parameter findings. Levels of MDA, SOD, CAT and GSH in the serum and tissue of all groups were measured and the results are presented in Table III. There was an increase in tissue MDA in the T-7 group compared with the S-7 group; however it was not significant. Serum MDA levels were significantly lower in the T-28 group compared with the S-7 group $(\mathrm{P}<0.05)$ and tissue MDA levels were significantly lower in the $\mathrm{T}+\mathrm{Q}-7$ group compared with the $\mathrm{T}-7$ group $(\mathrm{P}<0.05)$. A significant increase in serum SOD activity in the sciatic nerve was observed in the T+Q-28 group compared with the T+Q-7 group $(\mathrm{P}<0.05)$. Additionally, a significant decrease was observed in serum CAT activity in the T-28 group compared with the S-7 group $(\mathrm{P}<0.05)$. However, a significant increase was observed in serum CAT activity in the T+Q-7 group compared with the T-7 group $(\mathrm{P}<0.05)$. Serum GSH activity was significantly lower in the $\mathrm{S}-28$ group compared with the $\mathrm{S}-7$ group $(\mathrm{P}<0.05)$, however no statistically significant differences in GSH activity were observed among the other groups.

\section{Discussion}

Peripheral nerves may be exposed to various types of damage, including crush, compression and tension injuries (2). Major functional deficits occur when severed axons are unable to re-establish continuity with the distal aspect due to impairment of motor neurons, a surrounding environment hostile to Schwann cell survival and insufficient nerve regeneration capacity (23). Peripheral nerve trauma is therefore a 
Table II. Morphometric findings in the experimental groups.

\begin{tabular}{lcccc}
\hline Group & $\begin{array}{c}\text { Myelin sheath } \\
\text { thickness }(\mu \mathrm{m})\end{array}$ & $\begin{array}{c}\text { Nerve fiber } \\
\text { diameter }(\mu \mathrm{m})\end{array}$ & $\begin{array}{c}\text { Number of myelinated } \\
\text { nerve fibers }\end{array}$ & Apoptotic index (\%) \\
\hline S-7 & $2.66 \pm 0.28$ & $7.71 \pm 0.81$ & $75.33 \pm 7.31$ & $19.28 \pm 6.65$ \\
S-28 & $2.22 \pm 0.18$ & $7.95 \pm 0.55$ & $89.83 \pm 11.53$ & $27.69 \pm 3.75$ \\
Q-7 & $2.63 \pm 0.28$ & $7.88 \pm 0.81$ & $78.00 \pm 11.38$ & $20.64 \pm 6.96$ \\
Q-28 & $2.68 \pm 0.19$ & $7.19 \pm 0.70$ & $76.00 \pm 8.50$ & $26.68 \pm 4.77$ \\
T-7 & $0.92 \pm 0.22^{\mathrm{a}}$ & $4.08 \pm 0.83^{\mathrm{a}}$ & $51.66 \pm 5.08^{\mathrm{a}}$ & $71.64 \pm 10.33^{\mathrm{a}}$ \\
T-28 & $1.13 \pm 0.30^{\mathrm{b}}$ & $4.06 \pm 0.85^{\mathrm{b}}$ & $61.66 \pm 5.92^{\mathrm{b}}$ & $53.37 \pm 9.41^{\mathrm{b}}$ \\
T+Q-7 & $1.01 \pm 0.38$ & $4.37 \pm 0.35$ & $52.66 \pm 3.20$ & $43.91 \pm 7.51^{\mathrm{c}}$ \\
T+Q-28 & $1.46 \pm 0.05$ & $6.05 \pm 0.30^{\mathrm{d}, \mathrm{e}}$ & $73.50 \pm 12.67^{\mathrm{d}, \mathrm{e}}$ & $38.14 \pm 4.43^{\mathrm{d}}$ \\
\hline
\end{tabular}

Data are expressed as mean \pm standard deviation. $\mathrm{n}=6$ /group. ${ }^{\mathrm{a}} \mathrm{P}<0.05$ vs. the $\mathrm{S}-7$ group; ${ }^{\mathrm{b}} \mathrm{P}<0.05$ vs. the $\mathrm{S}-28$ group; ${ }^{\mathrm{c}} \mathrm{P}<0.05$ vs. the $\mathrm{T}-7$ group; ${ }^{d} \mathrm{P}<0.05$ vs. the T- 28 group; ${ }^{e} \mathrm{P}<0.05$ vs. the T+Q-7 group. S-7, sham 7-day group; S-28, sham 28-day group; Q-7, quercetin 7-day group; Q-28, quercetin 28-day group; T-7, trauma 7-day group; T-28, trauma 28-day group; T+Q-7, trauma+quercetin therapy 7-day group; T+Q-28, trauma+quercetin therapy 28 -day group.
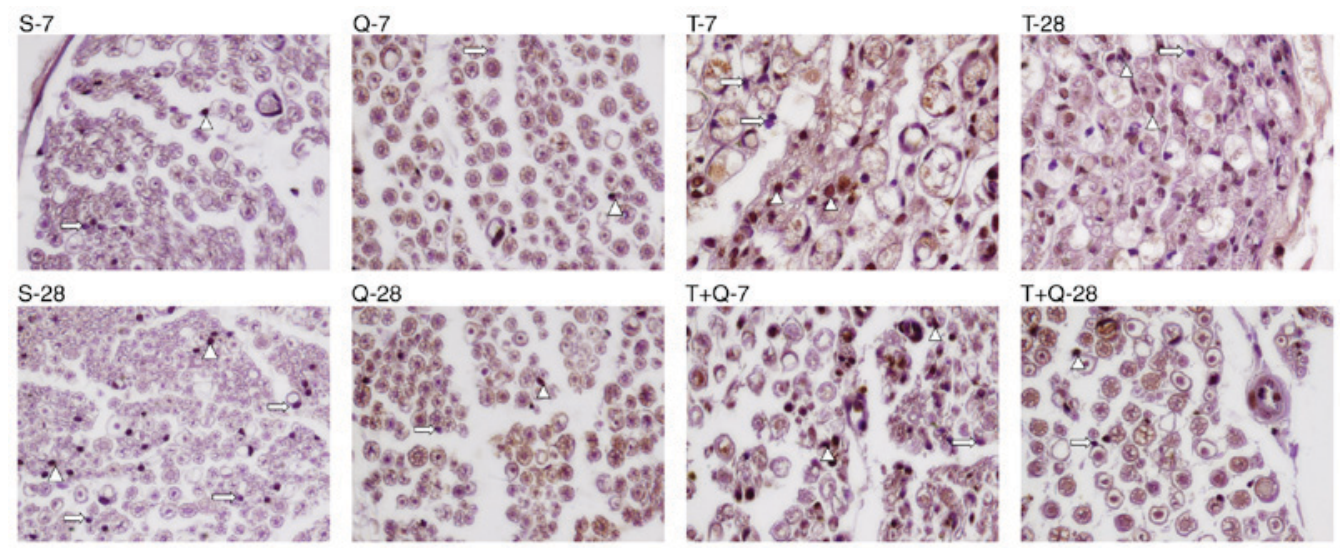

Figure 3. Terminal deoxynucleotidyl transferase deoxyuridıne triphosphate nick-end labeling assays were performed on Schwann cells to determine their apoptotic index values. Representative images from each group are displayed and notable features are indicated on the figure as follows: Apoptotic Schwann cell nucleus (arrow head), normal Schwann cell nucleus (right arrow). Magnification, x100. S-7, sham 7 day group; S-28, sham 28 day group; Q-7, quercetin 7 day group; Q-28, quercetin 28 day group; T-7-A, -B and -C; trauma 7 day group images -A, -B and -C; T-28-A, -B and -C, trauma 28 day group images -A, -B and $-\mathrm{C}$; $\mathrm{T}+\mathrm{Q}-7$, trauma+quercetin 7 day group; $\mathrm{T}+\mathrm{Q}-28$, trauma+quercetin 28 day group.

substantial health problem and is often difficult for clinicians to treat (23).

In addition to mechanical injury, nerve damage induced by clamps induces ischemia (7). One of the principal causes of functional loss following nerve compression is mechanical tissue crush occurring in the nerve (7). The crush type nerve injury model is the most widely used model for research into the cellular and molecular mechanisms of the peripheral nerve $(4,24)$. In the present study, a rat model was modified from a previous study (3) and utilized to investigate damage arising from sciatic nerve crush trauma.

The body weights of all animals in the present study were assessed throughout the experiment and significant increases were observed in all groups over the 4 weeks compared with baseline. However, no significant differences were observed among the groups. In a previous study on sciatic nerve damage in mice and rats, Vogelaar et al (25) observed that mice did not make full use of damaged claws until day 28 postoperatively and rats did not do so until day 70 . This suggests that the movement of animals is reduced due to an immobilization effect resulting from trauma and that the weight gain observed in the present study may be associated with this immobility.

Unlike the central nervous system, peripheral nerves may initiate a regeneration process at the injury site. Axonotmesis may be observed following crush injuries to nerves and Wallerian degeneration may occur distal to the injury in addition to axonal destruction, despite the integrity of the endothelial sheath being preserved. Although the functional outcome may be satisfactory due to spontaneous regeneration of the distal nerve stump, failure may also be observed due to nerve cell death and end organ atrophy $(26,27)$. Additionally, wounded tissue above the injury may mechanically block axonal extension and have an adverse impact on the healing process. Wallerian degeneration leads to the accumulation of macrophages and other white blood cells that assist with the removal of damaged axons, myelin sheath proteins and lipids in the damaged area. Furthermore, Schwann cells divide rapidly and produce dedifferentiated daughter cells that help 
Table III. Biochemical findings for the rat sciatic nerve.

\begin{tabular}{|c|c|c|c|c|c|c|c|c|}
\hline \multirow[b]{2}{*}{ Groups } & \multicolumn{2}{|c|}{ MDA } & \multicolumn{2}{|l|}{ SOD } & \multicolumn{2}{|r|}{ CAT } & \multicolumn{2}{|c|}{ GSH } \\
\hline & $\begin{array}{c}\text { Tissue } \\
\text { (nmol/mgr) }\end{array}$ & $\begin{array}{c}\text { Serum } \\
(\mathrm{nM})\end{array}$ & $\begin{array}{r}\text { Tissue } \\
(\mathrm{U} / \mathrm{g})\end{array}$ & $\begin{array}{c}\text { Serum } \\
(\mathrm{nM})\end{array}$ & $\begin{array}{l}\text { Tissue } \\
(\mathrm{kU} / \mathrm{mg})\end{array}$ & $\begin{array}{r}\text { Serum } \\
(\mathrm{kU} / \mathrm{l})\end{array}$ & $\begin{array}{l}\text { Tissue } \\
(\mathrm{mM} / \mathrm{gr})\end{array}$ & $\begin{array}{l}\text { Serum } \\
(\mathrm{mM} / \mathrm{l})\end{array}$ \\
\hline S-7 & $5.34 \pm 1.18$ & $0.28 \pm 0.07$ & $1,181.54 \pm 427.90$ & $0.45 \pm 0.32$ & $0.96 \pm 0.21$ & $1,131.04 \pm 330.50$ & $5.70 \pm 1.32$ & $0.02 \pm 0.007$ \\
\hline $\mathrm{S}-28$ & $3.52 \pm 1.11$ & $0.12 \pm 0.01$ & $1,432.13 \pm 266.67$ & $0.85 \pm 0.31$ & $1.09 \pm 0.17$ & $661.32 \pm 146.13$ & $10.45 \pm 2.31$ & $0.02 \pm 0.002^{\mathrm{a}}$ \\
\hline Q-7 & $4.29 \pm 1.77$ & $0.73 \pm 0.24$ & $1,127.72 \pm 48.72$ & $0.39 \pm 0.15$ & $1.08 \pm 0.19$ & $902.44 \pm 229.16$ & $5.61 \pm 2.22$ & $0.01 \pm 0.008$ \\
\hline Q-28 & $1.62 \pm 0.91$ & $0.29 \pm 0.19$ & $3,169.99 \pm 1,011.12$ & $1.37 \pm 0.31$ & $1.33 \pm 0.30$ & $561.10 \pm 155.72$ & $6.96 \pm 2.92$ & $0.02 \pm 0.002$ \\
\hline $\mathrm{T}-7$ & $6.82 \pm 2.81$ & $0.16 \pm 0.08$ & $2,226.54 \pm 976.69$ & $0.67 \pm 0.33$ & $1.02 \pm 0.26$ & $740.19 \pm 41.45$ & $4.99 \pm 2.11$ & $0.02 \pm 0.007$ \\
\hline $\mathrm{T}-28$ & $4.81 \pm 2.16$ & $0.06 \pm 0.03^{\mathrm{a}}$ & $3,290.18 \pm 2,122.73$ & $2.04 \pm 0.75$ & $1.09 \pm 0.19$ & $465.29 \pm 199.84^{\mathrm{a}}$ & $7.74 \pm 1.49$ & $0.02 \pm 0.003$ \\
\hline $\mathrm{T}+\mathrm{Q}-7$ & $1.71 \pm 0.79^{\mathrm{b}}$ & $0.39 \pm 0.16$ & $1,897.45 \pm 534.12$ & $0.27 \pm 0.25$ & $1.16 \pm 0.14$ & $992.43 \pm 113.96^{\mathrm{b}}$ & $6.54 \pm 1.63$ & $0.02 \pm 0.003$ \\
\hline $\mathrm{T}+\mathrm{Q}-28$ & $1.78 \pm 0.58$ & $0.40 \pm 0.14$ & $2,448.04 \pm 1,151.05$ & $1.04 \pm 0.12^{\mathrm{c}}$ & $1.30 \pm 0.30$ & $990.89 \pm 227.36$ & $6.29 \pm 1.62$ & $0.02 \pm 0.003$ \\
\hline
\end{tabular}

Data are expressed as the mean \pm standard deviation. $\mathrm{n}=6$ /group. ${ }^{\mathrm{a}} \mathrm{P}<0.05$ vs. the $\mathrm{S}-7$ group; ${ }^{\mathrm{b}} \mathrm{P}<0.05$ vs. the $\mathrm{T}-7$ group; ${ }^{\mathrm{c}} \mathrm{P}<0.05$ vs. the T+Q-7 group. MDA, malondialdehyde; SOD, superoxide dismutase; CAT, catalase; GSH, glutathione; S-7, sham 7-day group; S-28, sham 28-day group; Q-7, quercetin 7-day group; Q-28, quercetin 28-day group; T-7, trauma 7-day group; T-28, trauma 28-day group; T+Q-7, trauma+quercetin therapy 7-day group; $\mathrm{T}+\mathrm{Q}-28$, trauma+quercetin therapy 28 -day group.

remove components of the myelin and subsequently serve an active role in nerve regeneration by providing pathways for axon renewal (26-28). Peripheral nervous system regeneration may not always result in a full functional recovery; Galtrey and Fawcett (29) reported that axonal regeneration lasted $\sim 56$ days (2-3.5 $\mathrm{mm} /$ day) and that functional recovery occurred in 21-42 days. To be considered a fully functional recovery, axon diameter and myelin sheath thickness must return to normal values.

A rat model of crush type sciatic nerve damage was established in the present study and morphological evaluation was performed in the early ( 7 days) and late periods (28 days) Diffuse degeneration was observed in the axons and myelin sheath in the sciatic nerves of rats in the T-7 group. The normal concentric lamellar structure of the myelin sheath was compromised and myelin sheath lamellae were separated from one another and fragmented. Axonal swelling was particularly evident and certain axons were completely degenerated. These results are compatible with the results of previous studies investigating Wallerian degeneration $(30,31)$. Furthermore, in sciatic nerve sections from rats in the T-28 group, the axon and myelin sheath in certain axons had degenerated and the normal concentric lamellar structure of the myelin sheath was impaired; however in addition to this degeneration, the regeneration process had begun and nerve fibers in which myelin production had commenced were observed. Significant differences were observed between the trauma groups and the sham group in terms of the myelin sheath thickness, nerve fiber diameter and the numbers of myelinated nerve fibers. Previous studies have also reported histological changes, including in numbers of myelinated nerve fiber numbers and diameters of myelinated nerve fibers, following sciatic nerve damage (30-32). Yüce et al (2) examined the nerve tissues from rats exposed to crush type nerve damage using electron microscopy and reported the disorganization of myelin, the loss of myelinated fibers and the absence of myelin ovoids and cytoskeleton by the end of week 1 . By the end of the week 4 , the formation of several thin, myelinated nerve fibers had been reported and the presence of non-myelinated axons was also observed. Additionally, decreases in myelin sheath thickness, nerve fiber diameter and axon diameter were reported following light microscopic morphometric examination of tissues. This process demonstrates the stages of regeneration following nerve degeneration and also supports the results of the present study.

Noorafshan et al (33) reported a decrease of $30 \%$ in the proximal nerve and $36 \%$ in the distal nerve in terms of the mean myelinated nerve fiber diameter on day 28 following crush nerve damage. They also reported losses of $48 \%$ in the proximal aspect of the nerve and $56 \%$ in the distal aspect regarding the total numbers of myelinated nerve fibers. Another previous study reported findings compatible with Wallerian injury on days 7 and 28 following nerve damage (34). In the present study, the morphological injury findings that developed following crush type nerve damage were compatible with previous studies and may serve as a reference for further studies concerning the process and stages of regeneration.

Impairment of the vasa nervorum also occurs following sciatic nerve crush injury and if compressive ischemia is maintained over a sufficient period of time, blood flow to the nerve may not be restored (35). A number of different molecules, including endogenous chemical mediators, may be involved in the underlying pathology of sciatic nerve crush injury, in addition to ischemia, free radical production (35) and apoptosis $(36,37)$. Cellular damage induced by oxidative stress may trigger apoptosis. Free oxygen radicals (ROS) may trigger apoptotic or necrotic cell death as they exhibit lipid peroxidation (LPO) in catalytic reactions (38). ROS are regarded as an important source of LPOs and cause oxidative stress by triggering changes in a series of antioxidant activities $(39,40)$. Under normal conditions, cells are protected against oxidative damage by several mechanisms and antioxidant molecules (41). The antioxidant enzymes involved are SOD, CAT and glutathione peroxidase, while the cellular antioxidant defense 
mechanisms are low molecular weight GSH and vitamins C and $\mathrm{E}(41,42)$. SOD converts superoxide anion radicals into hydrogen peroxide $\left(\mathrm{H}_{2} \mathrm{O}_{2}\right)$, which is broken down by CAT in the peroxisomes and GSH peroxidase in the cytosol and mitochondria to form oxygen and water (43). GSH has been reported to be the primary functioning defense system as a scavenger and co-factor in metabolic detoxification of ROS against oxidative damage (38).

If damage occurs in a peripheral nerve, a response involving a series of biochemical changes is triggered. Serious injury may lead to neuronal edema, intensive neutrophil infiltration and apoptosis. Increased neutrophil infiltration causes an increase in myeloperoxidase activity and tissue MDA and LPO levels. LPO may directly impair membrane functions and indirectly harm cellular components (3). A significant increase has been observed in LPOs following injury (3). Hall and Braughler (44) reported peak LPO levels at 1, 2 and $48 \mathrm{~h}$ following spinal cord trauma. Oxidative stress is regarded as one of the main causes of nerve damage following injury. However, little is known about changes in antioxidant mRNA expression and changes following peripheral nerve injury and regeneration (45). In the present study, a small increase in the levels of tissue MDA was observed in the S-7 group compared with the T-7 group. However, serum MDA was significantly lower in the T-28 group compared with the $\mathrm{S}-7$ group. Tissue MDA levels were also significantly decreased in the T+Q-7 group compared with the T-7 group. There was a significant increase in serum SOD activity in the T+Q-28 group compared with the T+Q-7 group. Although no significant differences were observed between the trauma and sham groups, there was a notable decrease in MDA levels in the groups receiving quercetin. Several previous studies of sciatic nerve injury have reported an increase in MDA, a LPO marker $(3,46,47)$, however the results of the present study are not fully aligned with this. Furthermore, previous studies have reported that damage occurs due to ischemic and mechanical effects in crush type injuries in the sciatic nerve $(2,3)$. However, the severe histopathological injury observed in the present study was considered to be due more to a mechanical effect rather than ischemia and when combined with mild ischemic injury, caused increased morphological damage.

Mechanical, ischemic and inflammatory processes are initiated by nerve damage (2) and there are various treatments available to reduce their impact on nerve function. The effects of various treatment methods on nerve regeneration have been assessed in a number of studies and promising developments have been reported $(48,49)$. However, sciatic nerve damage is still clinically significant and the mechanisms involved are not fully understood. Sciatic nerve damage may have a negative impact on the patient's quality of life. The majority of the positive effects of quercetin in the prevention of several chronic diseases have been attributed to its antioxidant activity (50). Quercetin acts as an antioxidant by directly scavenging free radicals and also exhibits an indirect effect by binding to iron and copper and inhibiting the release of $\mathrm{H}_{2} \mathrm{O}_{2}$ and LPO caused by transition metals (51). In addition to its antioxidant activity, it has also been reported to possess a number of other essential functions, including anticarcinogenic, anti-ischemic, anti-inflammatory and antiallergenic properties (52). In addition to its other biological benefits, quercetin has been reported to contribute to the protection of neuronal cells against oxidative stress-induced neurotoxicity (53). Chen et al (54) described the effects of quercetin on sciatic nerve-crush injuries and the results suggested that quercetin accelerated the functional recovery of mice by upregulating neuronal intrinsic growth capacity and postponing distal atrophy.

Previous studies investigating the effects of quercetin on levels of antioxidant enzymes have reported that SOD ameliorates oxidative stress in the brain and that quercetin administered for 3 weeks significantly increased SOD levels in rats (55) and significantly reduced lipid peroxide levels (56). The neuroprotective mechanism of quercetin in cerebral ischemia causes a decrease in metalloproteinase- 9 and reduces free radical production (11). Although the neuroprotective effects of quercetin on the central nervous system have been evaluated, to the best of our knowledge no previous studies have investigated its effect on peripheral nervous system damage. In the present study, a significant decrease in tissue MDA levels was observed in the T+Q-7 group compared with the T-7 group. No significant differences were observed in myelin sheath thickness or nerve fiber diameters between the T-7 group and the T+Q-7 group. However, significant increases were observed in the myelinated nerve fiber numbers and nerve fiber diameters in the T+Q-28 group compared with the T-7 group. Significant increases were also observed in nerve fiber diameters and myelinated nerve fiber numbers in the T+Q-28 group compared with the T+Q-7 group. Although the stages of normal regeneration had begun in sections from the T-28 group, marked axonal and myelin injury were still present. A marked degree of axon-myelin regeneration was also observed in the T+Q-28 group and the nerve tissue morphology was almost as normal as that in the T+Q-7 group rats. These results suggest that quercetin notably shortened the healing period in a rat model of crush type nerve damage and positively contributed to early healing and productivity, partly via its antioxidant effects. However, the lack of association between the biochemical and morphological findings in the present study indicates that morphological damage may arise as a result of a direct mechanical effect extraneous to the nerve damage.

Schwann cells serve a major role in Wallerian degeneration. They become active during the initial $24 \mathrm{~h}$ following injury and undergo nuclear and cytoplasmic widening and an increase in their mitotic rate $(14,15)$. The primary role of the Schwann cell is to assist with the removal of degenerated axonal and myelin debris and their subsequent transfer to macrophages. Schwann cells and macrophages work together in phagocytosis and cleaning of the wound site in a process lasting between 1 week and several months (14-16). The incidence of apoptotic cell death in dorsal root ganglia neurons following axonotmesis is 20-50\% (16). Quercetin induces apoptosis, prevents tumor development, increases membrane fluidity, inhibits phospholipase A2 and protein kinases and protects the erythrocyte membrane against oxidative damage in mice (57). Bcl-2-associated x protein expression, caspase-3 and caspase- 9 activation and levels of p53 mRNA, a protein that regulates the cell cycle, increased significantly in a dose-dependent manner in neuroblastoma cells taken from mice administered with quercetin (58). Gholami et al (59) reported that quercetin may be beneficial in the treatment of 
sciatic ischemic/reperfusion injury due to its anti-apoptotic and anti-inflammatory effects and its ability to reduce the expression of nuclear factor $-\kappa \mathrm{B}$. In the present study, the AI in Schwann cells following sciatic nerve damage was significantly increased the T-7 and T-28 groups compared with the S-7 and S-28 groups, respectively. A significant decrease in AI was observed in the T+Q-7 group compared with the T-7 group and AI also significantly decreased in the T+Q-28 group compared with the T-28 group. According to these results, quercetin demonstrated a positive effect on crushing type sciatic nerve damage, exhibiting anti-apoptotic effects. These effects indicate that quercetin treatment may aid the regeneration of sciatic nerves.

Recovery rates of patients with peripheral nerve injury who undergo conventional surgical and medical treatments have been disappointing $(60,61)$. Previous studies have reported that natural medicine may stimulate nerve growth factor expression following nerve injury and promote peripheral nerve regeneration and functional recovery (60-63). These results indicate that natural medicine may be a novel method of promoting the repair of peripheral nerve injuries. Polymerase chain reaction (PCR) is a common laboratory technique used to make many copies of a specific DNA region in vitro (64). Klasan et al (65) reported that the Reg3 G gene serves a major role in communication between injured axons and muscles and may serve a significant role in skeletal muscle and peripheral nerve regeneration. Al-Jumaily et al (66) examined the expression of dorsal root ganglion (DRG) of members of three families of genes, which have been demonstrated to induce the $\mathrm{I} \mathrm{Cl}(\mathrm{Ca})$ current following injury and revealed that that mBestl and Tweety 2 were the best candidates to serve a role in the injury-induced $\mathrm{I} \mathrm{Cl}(\mathrm{Ca})$ in DRG neurons (66). Further studies are required to fully elucidate the process of sciatic nerve degeneration-regeneration. In addition, the use of PCR may be beneficial to indicate the presence of relevant molecules within the tissue.

In conclusion, the administration of quercetin 7 and 28 days following nerve damage exhibited an anti-apoptotic effect and a positive impact on nerve regeneration in the present study. Additionally, quercetin intake may shorten the Wallerian degeneration that occurs following crush-type nerve injury, accelerate myelination and partially reduce oxidative stress. Further studies are required to assess different dosages of quercetin and different application periods to determine its use as a novel treatment option within a clinical setting.

\section{Acknowledgements}

This study was supported by the Scientific Researches Fund of Karadeniz Technical University (grant no. TDK-2015-5331).

\section{References}

1. Wang W, Li D, Li Q, Wang L, Bai G, Yang T, Li Q, Zhu Z and Sun $\mathrm{H}$ : Erythropoietin promotes peripheral nerve regeneration in rats by upregulating expression of insulin-like growth factor-1. Arch Med Sci 11: 433-437, 2015.

2. Yüce S, Cemal Gökçe E, Işkdemir A, Koç ER, Cemil DB, Gökçe A and Sargon MF: An experimental comparison of the effects of propolis, curcumin, and methylprednisolone on crush injuries of the sciatic nerve. Ann Plast Surg 74: 684-692, 2015.
3. Yildirim AE, Dalgic A, Divanlioglu D, Akdag R, Cetinalp NE, Alagoz F, Helvacioglu F, Take G, Guvenc Y, Koksal I and Belen AD: Biochemical and histopathological effects of catechin on experimental peripheral nerve injuries. Turk Neurosurg 25: 453-460, 2015.

4. Gao Y, Weng C and Wang X: Changes in nerve microcirculation following peripheral nerve compression. Neural Regen Res 8: 1041-1047, 2013.

5. Roglio I, Bianchi R, Gotti S, Scurati S, Giatti S, Pesaresi M, Caruso D, Panzica GC and Melcangi RC: Neuroprotective effects of dihydroprogesterone and progesterone in an experimental model of nevre crush injury. Neuroscience 155: 673-685, 2008.

6. Beck-Broichsitter BE, Lamia A, Geuna S, Fregnan F, Smeets R, Becker ST and Sinis N: Does pulsed magnetic field therapy influence nerve regeneration in the median nerve model of the rat? Biomed Res Int 2014: 401760, 2014.

7. Schmelzer JD, Zochodne DW and Low PA: Ischemic and reperfusion injury of rat peripheral nerve. Proc Natl Acad Sci USA 86: $1639-1642,1989$.

8. Waseem M and Parvez S: Neuroprotective activities of curcumin and Quercetin with potential relevance to mitochondrial dysfunction induced by oxaliplatin. Protoplasma 253: 417-430, 2016.

9. Arikan S, Ersan I, Karaca T, Kara S, Gencer B, Karaboga I and Hasan Ali T: Quercetin protects the retina by reducing apoptosis due to ischemia-reperfusion injury in a rat model. Arq Bras Oftalmol 78: 100-104, 2015.

10. Yao RQ, Qi DS, Yu HL, Liu J, Yang LH and Wu XX: Quercetin attenuates cell apoptosis in focal cerebral ischemia rat brain via activation of BDNF-TrkB-PI3K/Akt signaling pathway. Neurochem Res 37: 2777-2786, 2012.

11. Sharma DR, Wani WY, Sunkaria A, Kandimalla RJ, Verma D, Cameotra SS and Gill KD: Quercetin protects against chronic aluminum-induced oxidative stress and ensuing biochemical, cholinergic, and neurobehavioral impairments in rats. Neurotox Res 23: 336-357, 2013.

12. Guide for the Care and Use of Laboratory Animals. National Research Council (US): Committee for the Update of the Guide for the Care and Use of Laboratory Animals. 8th edition. National Academies Press (US), Washington, DC, 2011.

13. Ferreira PE,Lopes CR, Alves AM, Alves ÉP, Linden DR, Zanoni JN and Buttow NC: Diabetic neuropathy: An evaluation of the use of quercetin in the cecum of rats. World J Gastroenterol 19: 6416-6426, 2013.

14. Hirata K and Kawabuchi M: Myelin phagocytosis by macrophages and nonmacrophages during wallerian degeneration. Microsc Res Tech 57: 541-547, 2002.

15. Mirajullah M and Shen X: Schwann cells: Leader of nervenkitt. J Ayub Med Coll Abbottabad 14: 30-33, 2002.

16. Burnett MG and Zager EL: Pathophysiology of peripheral nerve injury: A brief review. Neurosurg Focus 16: E1, 2004.

17. Di Scipio F, Raimondo S, Tos $P$ and Geuna $S$ : A simple protocol for paraffin-embedded myelin sheath staining with osmium tetroxide for light microscope observation. Microsc Res Tech 71: 497-502, 2008.

18. Yagi K: Lipid peroxides related radicals in clinical medicine free radicals in diagnostic medicine. Adv Exp Med Biol 366: 1-15, 1994.

19. Mihara $M$ and Uchiyama M: Determination of malonaldehyde precursor in tissues by thiobarbituric acid test. Anal Biochem 86: 271-278, 1978

20. Góth L: A simple method for determination of serum catalase activity and revision of reference range. Clin Chim Acta 196: 143-151, 1991

21. Sun Y, Oberley LW and Li Y: A simple method for clinical assay of superoxide dismutase. Clin Chem 34: 497-500, 1988.

22. Ellman GL: Tissue sulphydryl groups. Arch Biochem Biophys 82: 70-77, 1959

23. Karşıdağ S, Özcan A, Sahin S, Karşidağ S, Kabukçuoğlu F, Uğurlu K and Baş L: Electrophysiologic and histopathologic evaluation of peripheral nerve regeneration at different nerve segments and with different repair techniques. Acta Orthop Traumatol Turc 42: 278-283, 2008 (In Turkish).

24. Tos P, Ronchi G, Papalia I, Sallen V, Legagneux J, Geuna S and Giacobini-Robecchi MG: Chapter 4: Methods and protocols in peripheral nevre regeneration experimental research: Part I-experimental models. Int Rev Neurobiol 87: 47-79, 2009.

25. Vogelaar CF, Vrinten DH, Hoekman MF, Brakkee JH, Burbach JP and Hamers FP: Sciatic nerve regeneration in mice and rats: Recovery of sensory innervation is followed by a slowly retreating neuropathic pain-like syndrome. Brain Res 1027: 67-72, 2004. 
26. Glenn TD and Talbot WS: Signals regulating myelination in peripheral nerves and the Schwann cell response to injury. Curr Opin Neurobiol 23: 1041-1048, 2013.

27. Li R, Wu J, Lin Z, Nangle MR, Li Y, Cai P, Liu D, Ye L, Xiao Z, $\mathrm{He}$ C, et al: Single injection of a novel nerve growth factor coacervate improves structural and functional regeneration after sciatic nerve injury in adult rats. Exp Neurol 288: 1-10, 2017.

28. Wang Y, Shan Q, Meng Y, Pan J and Yi S: Mrpl10 and Tbp are suitable reference genes for peripheral nerve crush injury. Int J Mol Sci 18: pii: E263, 2017.

29. Galtrey CM and Fawcett JW: The role of chondroitin sulfate proteoglycans in regeneration and plasticity in the central nervous system. Brain Res Rev 54: 1-18, 2007.

30. Yin ZS, Zhang H, Bo W and Gao W: Erythropoietin promotes functional recovery and enhances nerve regeneration after peripheral nerve injury in rats. AJNR Am J Neuroradiol 31: 509-515, 2010.

31. Gigo-Benato D, Russo TL, Tanaka EH, Assis L, Salvini TF and Parizotto NA: Effects of 660 and $780 \mathrm{~nm}$ low-level laser therapy on neuromuscular recovery after crush injury in rat sciatic nerve. Lasers Surg Med 42: 673-682, 2010.

32. Gjurasin M, Miklic P, Zupancic B, Perovic D, Zarkovic K, Brcic L, Kolenc D, Radic B, Seiwerth S and Sikiric P: Peptide therapy with Pentadecapeptide BPC 157 in traumatic nerve injury. Regul Pept 160: 33-41, 2010.

33. Noorafshan A, Omidi A and Karbalay-Doust S: Curcumin protects the dorsal root ganglion and sciatic nerve after crush in rat. Pathol Res Pract 207: 577-582, 2011.

34. Jiang X, Ma J, Wei Q, Feng X, Qiao L, Liu L, Zhang B and $\mathrm{Yu}$ W: Effect of frankincense extract on nerve recovery in the rat sciatic nerve damage model. Evid Based Complement Alternat Med 2016: 3617216, 2016.

35. Morani AS and Bodhankar SL: Neuroprotective effect of vitamin E acetate in models of mononeuropathy in rats. Neuroanatomy 7 : 33-37, 2008.

36. Smith D, Tweed C, Fernyhough P and Glazner GW: Nuclear factor-kappaB activation in axons and Schwann cells in experimental sciatic nevre injury and its role in modulating axon regeneration: Studies with etanercept. J Neuropathol Exp Neurol 68: 691-700, 2009.

37. Maeda T, Kiguchi N, Kobayashi Y, Ozaki M and Kishioka S: Pioglitazone attenuates tactile allodynia and thermal hyperalgesia in mice subjected to peripheral nerve injury. J Pharmacol Sci 108: 341-347, 2008

38. Goraca A, Ciejka E and Piechota A: Effects of extremely low frequency magnetic field on the parameters of oxidative stress in heart. J Physiol Pharmacol 61: 333-338, 2010.

39. Ragy MM: Effect of exposure and withdrawal of $900-\mathrm{MHz}$ electromagnetic waves on brain, kidney and liver oxidative stress and some biochemical parameters in male rats. Electromagn Biol Med 34: 279-284, 2015.

40. Yurekli AI, Ozkan M, Kalkan T, Saybasili H, Tuncel H, Atukeren P, Gumustas K and Seker S: GSM base station electromagnetic radiation and oxidative stress in rats. Electromagn Biol Med 25: 177-188, 2006

41. Tkalec M, Stambuk A, Srut M, Malarić K and Klobučar GI: Oxidative and genotoxic effects of $900 \mathrm{MHz}$ electromagnetic fields in the earthworm Eisenia fetida. Ecotoxicol Environ Saf 90: 7-12, 2013

42. Meral I, Mert H, Mert N, Deger Y, Yoruk I, Yetkin A and Keskin S: Effects of 900-MHz electromagnetic field emitted from cellular phone on brain oxidative stres and some vitamin levels of guinea pigs. Brain Res 1169: 120-124, 2007.

43. Celino FT, Yamaguchi S, Miura C, Ohta T, Tozawa Y, Iwai T and Miura T: Tolerance of spermatogonia to oxidative stress is due to high levels of $\mathrm{Zn}$ and $\mathrm{Cu} / \mathrm{Zn}$ superoxide dismutase. PLoS One 6: e16938, 2011

44. Hall ED and Braughler JM: Effects of intravenous methylprednisolone on spinal cord lipid peroxidation and $\mathrm{Na}++\mathrm{K}+$ )-ATPase activity. Dose-response analysis during 1 st hour after contusion injury in the cat. J Neurosurg 57: 247-253, 1982.

45. Lanza C, Raimondo S, Vergani L, Catena N, Sénès F, Tos P and Geuna S: Expression of antioxidant molecules after peripheral nerve injury and regeneration. J Neurosci Res 90: 842-848, 2012.

46. Ozturk O, Tezcan AH, Adali Y, Yıldırım CH, Aksoy O, Yagmurdur $\mathrm{H}$ and Bilge A: Effect of ozone and methylprednisolone treatment following crush type sciatic nerve injury. Acta Cir Bras 31: 730-735, 2016.
47. Gutteridge JM: Lipid peroxidation and antioxidants as biomarkers of tissue damage. Clin Chem 41: 1819-1828, 1995.

48. Galloway EB III, Jensen RL, Dailey AT, Thompson BG and Shelton C: Role of topical steroids in reducing dysfunction after nevre injury. Laryngoscope 110: 1907-1910, 2000.

49. Lee M, Doolabh VB, Mackinnon SE and Jost S: FK506 promotes functional recovery in crushed rat sciatic nerve. Muscle Nerve 23: 633-640, 2000

50. Halliwell B and Gutteridge JM: Role of free radicals and catalytic metal ions in human disease: An overview. Methods Enzymol 186: 1-85, 1990.

51. da Silva EL, Piskula MK, Yamamoto N, Moon JH and Terao J: Quecetin metabolites inhibit copper ion-induced lipid peroxidation in rat plasma. FEBS Lett 430: 405-408, 1998.

52. Elik M, Serdaroğlu G and Özkan R: Mİrisetin ve kuersetin bileşiklerinin antioksidan etkinliklerinin dft yöntemiyle incelenmesi. CÜ Fen Bil Dergisi 28: 53-65, 2007.

53. Heo HJ and Lee CY: Protective effects of quercetin and vitamin $\mathrm{C}$ against oxidative stress-induced neurodegeneration. J Agric Food Chem 52: 7514-7517, 2004.

54. Chen MM, Qin J, Chen SJ, Yao LM, Zhang LY, Yin ZQ and Liao H: Quercetin promotes motor and sensory function recovery following sciatic nerve-crush injury in C57BL/6J mice. J Nutr Biochem 46: 57-67, 2017.

55. Hu QH, Wang C, Li JM, Zhang DM and Kong LD: Allopurinol, rutin, and Quercetin attenuate hyperuricemia and renal dysfunction in rats induced by fructose intake: Renal organicion transporter involvement. AM J Physiol Renal Physiol 297: F1080-F1091, 2009.

56. Raju TA, Lakshmi AN, Anand T, Rao LV and Sharma G: Protective effects of Quercetin during influenza virus-1nduced oxidative stres. Asia Pac J Clin Nutr 9: 314-317, 2000.

57. Pawlikowska-Pawlega B, Gruszecki WI, Misiak LE and Gawron A: The study of the quercetin action on human erythrocyte membranes. Biochem Pharmacol 66: 605-612, 2003.

58. Sugantha Priya E, Selvakumar K, Bavithra S, Elumalai P, Arunkumar R, Raja Singh P, Brindha Mercy A and Arunakaran J: Anti-cancer activity of quercetin in neuroblastoma: An in vitro approach. Neurol Sci 35: 163-170, 2014.

59. Gholami M, Khayat ZK, Anbari K, Obidavi Z, Varzi A, Boroujeni MB, Alipour M, Niapoor A and Gharravi AM: Quercetin ameliorates peripheral nerve ischemia-reperfusion injury through the NF-kappa B pathway. Anat Sci Int 92: 330-337, 2017.

60. YuJ,Zhang Y,SunS, ShenJ, Qiu J,YinX, YinHand Jiang S: Inhibitory effects of astragaloside IV on diabetic peripheral neuropathy in rats. Can J Physiol Pharmacol 84: 579-587, 2006.

61. Cheng CY, Yao CH, Liu BS, Liu CJ, Chen GW and Chen YS: The role of astragaloside in regeneration of the peripheral nerve system. J Biomed Mater Res A 76: 463-469, 2006.

62. Zhang $X$ and Chen J: The mechanism of astragaloside IV promoting sciatic nerve regeneration. Neural Regen Res 8: 2256-2265, 2013

63. Tohda C, Tamura T, Matsuyama S and Komatsu K: Promotion of axonal maturation and prevention of memory loss in mice by extracts of Astragalus mongholicus. Br J Pharmacol 149: 532-541, 2006.

64. Pilotte N, Papaiakovou M, Grant JR, Bierwert LA, Llewellyn S, McCarthy JS and Williams SA: Improved PCR-based detection of soil transmitted helminth infections using a next-generation sequencing approach to assay design. PLoS Negl Trop Dis 10: e0004578, 2016.

65. Klasan GS, Ivanac D, Erzen DJ, Picard A, Takasawa S, Peharec S, Arbanas J, Girotto D and Jerkovic R: Reg3G gene expression in regenerating skeletal muscle and corresponding nerve. Muscle Nerve 49: 61-68, 2014

66. Al-Jumaily M, Kozlenkov A, Mechaly I, Fichard A, Matha V, Scamps F, Valmier J and Carroll P: Expression of three distinct families of calcium-activated chloride channel genes in the mouse dorsal root ganglion. Neurosci Bull 23: 293-299, 2007.

This work is licensed under a Creative Commons Attribution-NonCommercial-NoDerivatives 4.0 International (CC BY-NC-ND 4.0) License. 